\title{
Oration
}

\section{Understanding the hand: A paradigm for research as self-education}

\section{H. Srinivasan}

Address for correspondence: Dr. H. Srinivasan, First Seaward Road, Chennai - 600 041. E-mail: srinih@ vsnl.com

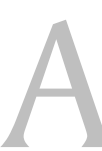

$\mathrm{n}$ invitation to deliver the Prof. Venkataswamy Oration is a great honour and the list of speakers of previous years starting with such "greats" as Dr. Kleinert attests to that. I am thankful to those responsible for bestowing this honour on me. However, it also implies relentless passage of time and a subtle change in one's status to that of "an elder" who should be having profound and precious things to say about the past and future. To quote an eminent physiologist, 'I must confess at the outset that the pearls of wisdom within my shell have been slow to mature, and they are still too small to spread' before this young, eager and learned audience and 'I can only use them as decorations for a personal narrative. ${ }^{1}$

“. . . Mine is a story fraught with a series of fortunate circumstances and fortunate decisions, for I can lay claim neither to distinguished forbears nor to a capacious mentality. . ."

Joseph Erlanger ${ }^{2}$

The examiners of the University of Madras, during my career as medical student (1946-1951), have always evaluated me consistently as 'second class' and the numerous examiners of the Royal College of Surgeons of Edinburgh and those of the Royal College of Surgeons of England have also confirmed my secondclass status. The question "How can a certified secondclass man accomplish anything that deserves to be recognized with the award of an Oration like this?" would naturally arise in your minds. As there are a lot more second-class persons in this world than first class ones, perhaps some of the younger members of the audience may be encouraged by the answer. It is almost twenty years since I retired from my position as Senior Orthopædic Surgeon at the Central Leprosy Teaching and Research Institute at Chengalpattu, and thirteen years since I retired from research administration and guidance as Director, Central JALMA Institute for Leprosy (ICMR), Agra. I had already conveyed whatever technical information I had to convey through papers and articles in journals and chapters in books; and I have hardly anything new to say about the hand in motor paralysis, or the hand as an organ of sensibility or about certain aspects of functional morphology of the hand which were either familiar to me or to the elucidation of which I might have made some small contribution. When I took stock a few years ago of what I had achieved (a sure sign of growing old), I found that my contribution to the store of knowledge was not only meagre but was also quite ephemeral. Late in my life I realized that self-education more than additions to knowledge was the consequence of my attempts at research and efforts at understanding the hand. I also realized that how one did the research was far more important than what one got out of it. If you are lucky, your achievements are appreciated, publicized, magnified and you even become "famous". I was lucky not only in that manner but in many other ways.

Venkataswamy Oration delivered at the annual meeting of the Indian Society of Surgery of Hand in 2003. 
"Catch 'em young and train 'em hard" applies to research workers as much as it does to Circus animals.

I got interested in science very early. The year was 1941 and it was still three months to go for me to be 12 years old. In the first hour of my optional subject in the high school, which was physics (I was hopelessly bad in mathematics and I had to opt for physics as no other science subject was offered in that small-town high school). Our physics teacher, TPG as he was known by his initials, explained to us the Vernier scale. And I was hooked to Science then and there! I was amazed at the ingenuity of man who could devise a scale within a scale and effortlessly extend the sensitivity of the original scale, may be tenfold!

At that stage of my life, "Science" meant to me measurement and the ability of man to reach hidden depths of knowledge through sheer cleverness. My resolve to study Science was strengthened when I saw for myself the regularity underlying natural phenomena. While doing experiments on light, I could see that the angles of incidence and those of reflection were equal and that the image in the plane mirror was located exactly where it was supposed to be. And this was so with many other experiments, for example in heat and other areas of physics. I could see that Science was an effort to understand the world around us using a rigorous method of experiment. And that experiments were preparations for measurements.

\section{Amazing Anatomy \\ Mystery of Embryology \\ Fascination of Physical Anthropology \\ Sweep of Evolutionary Biology \\ Intricacies of Microscopic Anatomy \\ Logic of Functional Morphology \\ Thrill of Experimental Embryology Excitement of Comparative Anatom}

As a medical student, I was drawn early in the course to anatomy, of all subjects. For one thing, it gave me scope to indulge in my hobby, which was drawing. Second, our Professor, Dr. Aiyer, was an eloquent speaker whose advocacy made the subject very interesting. Through his spellbinding lectures anatomy ceased to be, for me at least, a smelly and messy matter of dissecting dried up dead bodies or a tiresome catalogue of incomprehensible Latin names that had to be gotten by heart in various permutations and combinations. I was attracted by the amazing sweep of anatomy that ranged from embryology to evolution and origin of man. My fascination for anatomy was strengthened when I read Dr. PK Duraiswamy's long paper in the Journal of Bone and Joint Surgery describing his experimental work of insulin induced congenital deformities in chicken, which fetched him the Robert Jones Medal in 1950 or ' 51.

Half a century ago Medicine was relying mostly on primitive $19^{\text {th }}$ century Pharmacy.

Surgery was mostly ablative, like the

"Off-with- his- head" remedy of Queen of Hearts.

I must confess that I was not drawn to medicine, which to me appeared like a lot of mumbo jumbo based on primitive pharmacy bordering on magic. Surgery, though more colourful and impressive because of its costume, rituals and gore and entertaining display of eccentric egos, did not attract me that much either, for it seemed not very different from the aggressive sadism of the queen of heart's 'off-with-his-head' variety.

\footnotetext{
“ Mismanagement of an injured finger may have as serious a consequence to the patient as mismanaged appendicitis “
}

Dr. V.R. Thayumanaswamy Professor of Orthopædics Madras Medical College (1951)

My views changed radically during my posting in Orthopædics. I realized that not all surgery was ablative and here was a branch of surgery which aimed at restoring function by restoring structure, an attitude that appealed to me very much. A casual remark by our professor of Orthopædic surgery, Prof. Thayumanaswamy, about the disastrous consequences of improperly treating an apparently trivial injury to an apparently trivial organ namely, the finger, sowed the seed of interest in me to understand the hand better at some future date, although I was not fully aware of that at that time. In any case, I decided to 
become an Orthopædic surgeon if I could not become an anatomist.

"People are generally better persuaded by reasons they themselves have discovered than by those which have come into the minds of others"

Blaise Pascal Philosopher Scientist

For reasons I need not go into here, I did not become an anatomist and I decided to do FRCS, preparatory to becoming an orthopaedic surgeon, instead of MS, although I got selected for the latter course in 1954. I spent an academic year (1953-1954) at Christian Medical College, Vellore, as Tutor of Anatomy under Prof. Liza Chacko, mainly to learn anatomy for the Primary FRCS exam and also to save some money to meet my initial expenditures in UK. That was a fateful decision and that year's work was a crucial one in my life for, it was during that year that I was introduced to research thanks to Prof. Liza Chacko, and again thanks to her, I presented my first research paper to a learned audience, I got to know about writing scientific papers for publication and I came across that wonderful book on hand by Wood-Jones, ${ }^{3}$ as a result of which I fell in love with hand and its anatomy. Prof. Liza Chacko had had her doctorate in Anatomy from Oxford and she was greatly interested in doing research in her discipline. Her main area of work had something to do with optic pathways. She was also the Editor of the Journal of Anatomical Society of India at that time. For some unknown reason, she asked me to be her Editorial Secretary (an honorary office with no remuneration!), which I willingly accepted although I knew nothing about editing or writing scientific papers. In order to do my job properly and also to avoid being taken to task by the authors of the papers for any mistakes on my part, I had to read up about how papers should be written up for publication as well as learn to avoid common grammatical and other errors. I also learned to read proofs and edit them. That was a good training ground and saved me a lot of trouble in many of my later endeavours.

It was around August or September 1953; I was just about, not quite, 24 years old at that time. One fine morning Prof. Chacko told us that we had to present short papers at the Annual meet of the Anatomical Society of India, which would be held at Hyderabad, along with the Indian Science Congress during the first week of January 1954. I was horror stricken and excited at the same time. There were hardly three months to go, and I had never even imagined doing anything like that before, and had no idea as to what to do, neither what topic to choose nor how to proceed further. Prof. Chacko suggested, rather vaguely, that I could take up some problem relating to the chameleon, as there were many specimens of that animal in the department.

\section{“...It is tortoises all the way down, young man!” as the old lady told the young man who asked her what supported the tortoise that supported the elephant that was holding the earth up.}

After thinking about it, I decided to study the mechanism of its tongue, because I thought I could do that within the time available. I studied the available material on reptiles and lizards including the great textbook of Zoology by Prof. JZ Young, about the tongue of the chameleon, which the animal whips out like a lash to catch its prey. That exercise taught me the good lesson that books, even renowned textbooks, were not necessarily sources of reliable information. They copy statements from earlier works and that may go a long way backwards, like the tortoises that supported the earth. In this case the books said that sudden engorgement with blood was the mechanism of projection of the tongue of the chameleon. A cursory glance at a section of the tongue would have shown that there were no large veins or venous sinuses in the tongue that could get filled with blood. Secondly, anybody who had watched the animal lash out its tongue, aiming it precisely at the prey and withdrawing it, all in such a short time that one can hardly see it, would know that it would be impossible to achieve that feat by filling and emptying the tongue with blood. In spite of all this, textbooks have been carrying that statement for God knows how many generations. For all I know, it might have started with Aristotle!

It is a thrilling feeling to have discovered something new - a new fact, which nobody else in the world knows, except you. 
I did the dissections and "discovered" the muscular mechanism and how the tongue musculature acted. I wrote up the investigation as a small paper and read it at the Conference as scheduled. It felt very great and I also felt very proud as if I had achieved something wonderful.

[ carrying out scientific research provides] "the excitement of the effort to understand the world ..."

John Dewey Philosopher

Later, when I read about the 'excitement of the effort to understand the world' I could understand what exactly the author was referring to as I had experienced it myself.

"This was my first taste of real research and I loved it"

Julius Axelrod ${ }^{4}$ Pharmacologist / Biochemist, Nat. Inst. Mental Health. USA

As one can well believe, it also gives a tremendous boost to one's self-esteem, like winning a medal in the Olympic Games!!

"Nothing looks more like an important new discovery than a poorly conducted experiment"

Joseph Mayer ${ }^{5}$

However, I must mention here that the 'thrill of discovery' does not depend upon the truth or correctness of the discovery. "False discovery" due to an experiment gone astray or wayward logic can give you the same kind of thrill as a "true discovery" except that one sobers up when one realizes the error. Even Nobel laureates have fallen victim to rejoicing on discoveries based on experimental errors or conceptual misconstructs and believing them to such an extent because of their 'gut feeling' that they had persisted in their error to the detriment of their reputation as scientists!

Two attitudes, rooted in our culture and tradition, militate against developing a desire for research.

They are: (i) GURU complex, and (ii) “ Because-I-say-so ” syndrome
There is an attitude among many medical teachers that at the undergraduate stage, the student should be fed with information as undisputed truths. Many of them will take offence if the student questions them, as if the ignorant student is contesting the omniscient teacher's wisdom. I call this "Guru complex" and it appears to be the relic of our age-old concept of knowledge as revealed truth. According to this, there are only the so-called facts, which the Guru knows and will transfer it to the student. We are all indoctrinated to revere the words of the Guru like words of God. This attitude simply smothers any curiosity and extinguishes any desire to find out or verify the facts oneself. Compare this with the long-standing practice in the West of the medical student participating in research projects actively in the process of data generation, collation and analysis.

"Srinivasan, so long as you are in the final year [of MBBS class], ALL cases of cerebral hæmorrhage will die!"

Dr. $x \quad x \quad x \quad x \quad x \quad x \quad x \quad x \quad x \quad x$

A Prof. of Medicine Madras Medical College (1951)

When I was a final MB student, one of the Professors of Medicine, a very popular teacher and reputed to be a very learned person and also said to be doing research, was taking a bedside clinic on strokes. He told us that stroke resulted from cerebral thrombosis or haemorrhage, the difference between the two being the patients having stroke due to bleeding die. I wondered how one could die if the haemorrhage was "very very small". When I had the temerity to raise this question, I was told that all cases of cerebral haemorrhage will die so long I was in the final year! It reminds one of the student's answer to the school inspector that the earth was 'square on Sundays and round on weekdays' because his teacher had told the class that the earth looked like his snuff-box (the teacher used two snuff-boxes-a round one on weekdays and a square one on Sundays).

"Keep the goals of your research simple and clinically relevant, even if the methods of investigation have to be complicated"

Mr. Ruscoe-Clarke

Birmingham Accident Hospital (1951) 
By chance, I got an opportunity to work under Mr. Ruscoe-Clarke at Birmingham Accident Hospital, the only hospital in the UK at that time wholly devoted to trauma including burns. As may be expected, "shock" was a major topic of research in that institution. I was impressed by Ruscoe-Clarke's approach to research, which was clinical and at the same time based on measurement using simple techniques possible for all. His methods of assessment of blood loss are good examples of this approach. For example, he showed that a handful of blood clot represented about half a litre of whole blood, and that an increase in the circumference of the thigh at its middle by one inch indicated increase in the volume of the thigh by about a litre, due to, say, bleeding from a fractured femur.

"Mechanical defects need mechanically sound solutions

"Keep standardized photographic records of clinical information

“We need 'Registrar Operations', not 'Super Surgeons'

Mr. Denis Browne

The Hospital for Sick Children (1958) Great Ormond Street, London.

Similarly, at a later stage in my career in UK, I worked under Mr. Denis Browne for about 20 months as Senior House Officer and Registrar. Attention to details and accuracy in recording clinical observations and looking at problems of deformities in limbs as mechanical derangements needing mechanically sound solutions were the two major lessons I seemed to have imbibed from this great pioneer of paediatric surgery, although I did not realize it at that time. As an example of the former, he insisted on photographic records of deformity. In the case of cleft-lip, he had standardized how the photograph was to be taken so that pre- and post-operative pictures were truly comparable. I remember he would reject the photograph if both ears were not visible and individual eyelashes were not seen distinctly! Another feature that appealed to me even at that time was his philosophy of 'Registrar Operation'. Denis Browne had a highly creative mind that invented a new operation or splint for practically every condition he dealt with. He held that any procedure devised should give reasonably good results and should also be easy enough to be performed by one's registrar or any other surgeon with average competence. He also held that it was no use devising an operation that would give superb results, but only in your hands!

"Do not ask ... what leader I follow. I am not bound to revere the
word of any particular master"

Motto of Royal Society

(Free translation from Latin')

I must confess that I did not take any surgical postgraduate course in UK, nor did I have systematic training in any field or discipline in which I worked later, be it orthopaedics, hand surgery or reconstructive surgery in leprosy. In all these areas, I was mostly selftaught, by studying the literature, by analysing my own experience and to a limited extent by critically observing others. I did not have the advantage of a long apprenticeship under one or more great masters either, as I was lucky enough to become a "chief" in June 1959, three months before I was 30 years of age. Self-learning has its advantages, but it also carries its disadvantages. The advantage was that I learned to be self-critical, probably more so than others. One disadvantage was that I had to learn everything the hard way, from my own mistakes. Another disadvantage in self-learning was one tended to neglect topics in which one was not particularly interested. Thus, one's area of expertise tended to become rather patchy, like the curate's egg. That would be avoided to some extent if one had post-graduate teaching responsibility, a privilege that I had denied myself for the sake of working full-time in my chosen field.

"As the wise test gold by burning, cutting and rubbing it on a piece of touchstone, so are you to accept my words after examining them and not merely out of regard for me..."

Gautama, the Buddha

One other advantage I had, which I think compensated to some extent some of the disadvantages of selflearning, was that I was not overawed by "authorities". The need to examine issues critically, without being influenced by the stature of the "Guru" was stressed so well more than 2500 years ago by Gautama, the Buddha as can be seen from the passage cited above, although he was by no means a modest person as far 
as his own estimate of the worth of his message to mankind was concerned! Dr. Paul Brand, the pioneer in the field of corrective surgery in leprosy, was a towering and charismatic personality and such an eloquent and persuasive speaker that one had to be extremely vigilant to be able to critically examine his statements. I think, that I had not trained under him helped me in this regard. I will come back to this later.

Learn to look at a problem differently. Some lateral thinking helps.

Keep 'Occam's razor' (the principle of parsimony) in mind. "Thou shalt not multiply causes unnecessarily"

Movement is not an end in itself as we are generally taught to believe. It is only a means to achieve an end.

Some kind of lateral thinking and looking at a problem from different, not necessarily orthodox, view points often helps. And secondly, one should always keep 'Occam's razor' or 'the principle of parsimony' that states, "thou shalt not multiply causes unnecessarily" in mind.

I got stuck in my investigations when I wanted to study the movement pattern of intrinsic minus fingers, for I wanted to verify Brand's categorical statements on this matter (and the applicability of Landsmeer's biarticular model). I could see from Brand's writings that he had not critically examined this issue and had gone by visual observations. My problem was "How does one investigate a movement?" For orthopaedic surgeons and equally for hand surgeons as well, "Keep moving" is the motto and mantra, as much as 'jarugandi' is for the attendant at Lord Balaji's presence at Tiumala. In fact our professional goal, it is dinned into our ears, is to maintain movements at joints. But I was stumped here on the issue of how to investigate the movement pattern of fingers when some muscles moving the finger were paralysed. When one thinks of movement, concepts like its direction, speed, acceleration etc., come to one's mind, but they were not relevant to my purpose. I took motion pictures of moving fingers, but did not know how to proceed further. The impasse continued till I changed my view of movement and looked at it as one would look at the transport system, as a means and not as an end in itself. If one looks at movements at joint systems as means for achieving some ends, then one can assess them in terms of their efficiency in achieving those ends.

Movement is the means by which a joint system changes from one stable posture to another.

We all know that all movements start from a particular position or posture of the joints, i.e., from a starting position, and end with the system in a different end position. Therefore, one may look upon movement as the process by which a joint system changes its state, shifts from one posture to another posture. But with this shift in my viewpoint, though it was no great discovery at all, I could now proceed to investigate movement in terms of postures. Using relevant coordinates, I found that I could represent the finger postures as points in a grid. Therefore, I could plot the starting posture, end posture and intermediate postures as so many points. And, lo and behold, by serially connecting these points, I get a line (which I called "finger dynamo gram") that would represent a particular movement. A line in a graph sheet is an objective entity with dimensions and amenable to mathematical treatment! One apparently small change in the viewpoint thus opened up a vista of possibilities some of which I could use, including that of investigating the roles of concerned muscles, and verifying our inferences by already available electromyographic information. Besides active contributions from muscles, one could also see the effects of the so-called passive forces resident in soft tissue structures.

\footnotetext{
'Burton's Law'

"However many hens sit on however many eggs for however long, nothing creative will result unless the eggs are fertilized... Fertilization only occurs when there is interaction between different kinds of fowl."
}

A C Burton ${ }^{7}$

I came across a collection of autobiographic essays of a number of scientists from various fields about their professional life. Going through their life histories, one is struck by their fraternization and how the crosspollination of ideas and collaborative research of scientists from different countries and institutions 
helped the individual's intellectual growth. For various reasons, we in India do not have many opportunities for such interactions. I was lucky in that I had a limited opportunity to work with Prof. JMF Landsmeer of University of Leiden in Holland, Hans to his friends, an authority on the anatomy of hand, who had elaborated the biarticular bitendinous tendon displacement model for the articular system of the finger. Hans was immensely interested in our application of his model to the living finger as all his work has been on cadaver fingers or mathematical models of "simplified fingers". In spite of his eminence in his field he was not patronizing towards us and probably for that reason we got along well with each other initially and became good friends later, at family level. Even now I do not know whether he was right or not, but I found his model useful for clinical application, for understanding finger deformities and for developing methods for correcting them. His views strongly coloured my own approach to the problem of deformities of finger and their correction. Not only could I develop the extensor diversion graft operation ${ }^{8}$ as a rational alternative for claw finger correction, but also devise the methodology to assess the procedure based on finger dynamography, clarify the conditions for stability of the thumb ${ }^{9}$, explain the deformities of the thumb in ulnar paralysis and combined paralysis of ulnar and median nerves ${ }^{10}$ and devise procedures to correct them, all on the basis of his model. I found I could apply his concept of "working space' of the hand and develop an objective twodimensional representation of the same for fingers, again using the method of finger dynamography. When my friend Dr. Buck-Gramcko asked me for a paper for the Hand Surgery journal he was editing, I wrote up about finger dynamography ${ }^{11}$, which he published with hardly any change. Unfortunately, that journal apparently had limited circulation, at least at that time, and to my great disappointment my paper lies buried in it instead of reaching the audience I expected it to do. In any case, I can personally vouchsafe to the veracity of the so-called 'Burton's Law'.

"...learn to do the drudgery that Science involves..."

I. P. Pavlov

Physiologist/Nobel Laureate

In my student days, in the physiology department of
Madras Medical College, there used to hang on the wall a framed copy of Pavlov's exhortation to young scientists. Among other things, he says this, "learn to do the drudgery that science involves". The drudgery he refers to is primarily related to data generation and collation. Writing up a project proposal can be an interesting exercise and so can also data analysis be. However, data generation and collation is a tedious affair and there is no escaping that. One cannot delegate it to somebody else, even if that person is a senior assistant of yours, unless that person is interested in the project and the problem you are investigating as much as you are. If you are not able to generate that kind of interest, it is best that you undergo this 'drudgery' yourself in order to ensure the quality of data.

Evidence and logic are the brick and mortar for uilding the edifice of scientific knowledge. We are humble masons who keep adding to the edifice and replacing the old and worn out bricks.

Science is based on data and is built up of concepts that explain the data. New data come up and ask to be explained, and in that process concepts change and this goes on and on. The drudgery mentioned by Pavlov is the essential process of collecting the bricks for the edifice of Science and it can be quite tedious, but that has to be gone through.

"The greater the intellect one has, the more originality one finds in men. Ordinary persons find no difference between men..."

Blaise Pascal

In the common clinical situation, data collection begins when one notices a discrepancy, a result or a finding different from the usual or the expected. And then one says, 'let us see how common this is' and an investigation starts. For example: the general perception is that treatment of Colles fracture generally gives good results. Is that so? What do we mean by good results? Bony union? Morbidity-free hand? Absence of disability? Any residual symptoms? Let us find out. And so starts an enquiry. All because one came across one patient who, when asked about it, complained of numbness and burning pain in the fingers six months after the injury and the X-ray had 
shown good union in good position.

"The odd thing is the dog did not bark ..."

Sherlock Holmes in ' Hound of Baskervilles'

It is the ability to spot the slightly different one from the usual that is basic to scientific observation. Like that of Sherlock Holmes who asked Dr. Watson about the odd behaviour of the dog. I had no time to verify the exact wording of the conversation, but it goes something like this.

Holmes: Did you notice the odd behaviour of the dog, Dr. Watson? Dr. Watson: No, I didn't notice any. In fact it had not done anything. Holmes: Exactly, that was the odd behaviour. The dog did not bark, it should have barked, shouldn't it?

One should have curiosity and pay attention to details to enable one to spot the odd thing or phenomenon. Always remember the dog that did not bark.

The Scientific Mind is one that is Nimble and Versatile enough to Catch the Resemblance of Things and at the same time Steady enough to Fix and Discern their Subtle Differences and Endowed by Nature with the Desire to Seek Patience to Doubt, Fondness to Meditate Slowness to Assert, Readiness to Reconsider Carefulness to Set in Order neither affecting what is New, nor Admiring what is Old and Hating Every Kind of Imposture

Francis Bacon ${ }^{12}$

Francis Bacon put it all succinctly and clearly, if quaintly, by saying that the scientific mind is one that was 'nimble and versatile enough to catch the resemblances of things' and at the same time 'fix and discern their subtle differences' and should also be 'endowed by nature with the desire to seek'. He goes on to add other qualities such as patience to doubt, fondness to meditate, slowness to assert but readiness to reconsider, carefulness to set in order and neither affecting (meaning loving-as in affection) what is new nor admiring what is old and hating every kind of imposture-meaning humbug and fraud, qualities which we as a race seem to be sadly lacking.
Writing Helps to Discipline one's thinking Regulate one's praxis Audit one's work Communicate one's views

Most people consider writing up a project report or a paper as a burden. I found writing up project proposals at the commencement of and project report at the completion of a piece of work a good exercise. This was so irrespective of whether one was soliciting funds from any agency for the project or not. It is very beneficial to put one's ideas to paper so that any wooliness and loose logic in thinking is made visible. Periodic evaluation of one's results of treatment of various conditions serves well as work audit and identify areas of weakness, even if one is not publishing the findings.

"Money is like muck*. It is no good unless it is spread."

Francis Bacon

[* manure]

People forget that scientific work is very much like that of artists. While one may do a piece of work for the sheer joy of it, once completed, it no more belongs to the maker alone. In science it is even truer than in arts, for scientific work not validated is like the soul in limbo, or, to give a scientific simile, it is like Schrodinger's cat, neither alive nor dead! And a work can be validated only if it is made public. The goal of science is to add to knowledge, that is to improve our understanding of some aspect of the world around us and for that purpose, like money, knowledge must also be spread.

"When it comes to writing, scientists are no better than their secretaries..."

Chauncey D Leake ${ }^{13}$

Writing is an ability that is quite different from formulating a research project or doing an experiment in the lab or doing a sophisticated surgical procedure. Like any other ability it has to be acquired and developed. Doctors are notorious as communicators because they fail to think in ordinary language. I now find that people working in the field of information science are impossible to talk to as they seem incapable of thinking and talking in any language but their own 
jargon. So, doctors now come as the second worst communicators, which is bad enough.

"A great fault of a scientist is that he may have so well in mind what he intends to say that he is inattentive to what his sentences actually say..."

Wm. Mansfield Clark ${ }^{6}$

This is the not the place for me to explain the techniques of good writing, common errors that must be avoided etc. But I would like to say one thing in this context. One should try one's best to keep the writing simple, by which I mean keep the writing free from jargon to the extent possible. Imagine you are addressing an audience of intelligent laypersons or paramedicals and that you are trying to explain your work to them. I remember reading somewhere the following advice to aspiring authors: "Strike off all adjectives first". I will add: "next, strike off all technical terms". I feel these are sound pieces of advice and, generally, I have tried to follow them, to the extent possible.

"Never defend anything you have written against the accusation that it is not clear enough. If a conscientious reader finds a passage unclear, it has to be re-written." Karl Popper ${ }^{14}$

Philosopher of Science

The above is another piece of sound advice. One should never hesitate to revise or re-write if 'a conscientious reader' (as Popper nicely puts it) complains of obscurity or verbosity. Remember, one's first draft is usually the worst draft although to oneself it appears as one of the best pieces of writing worth at least a Pulitzer Prize. Ordinarily, I find I have to make four revisions, i.e., five drafts, of a paper, before I think it fit for sending to a journal for publication. Sometimes it takes more and a few times one or two less, but five was the average.

"Even the dogs may eat the crumbs which fall from the rich man's

table; and in these days when the rich in knowledge eat such specialized food, at such separate tables, only the dogs have a chance of a balanced diet."

Sir Geoffrey Vickers ${ }^{15}$
I came across the above comment during one of my 'wild' readings and I thought it worth sharing with you as it is not only a very relevant piece of advice applicable to us, but also because Vickers has so well expressed what I had in my mind but did not know how to put. I am one of the victims of narrow specialization and I have always felt that I have suffered from intellectual and educational malnutrition and consequent deficiency disorders. And, I have tried to compensate by taking supplementary nutrition by way of extending my reading horizons. This, I have found profitable and enjoyable, and I recommend the same to any of you who feels the same way. I assure you that it will be a welcome relief from the treadmill life that many of us are forced to lead, like the proverbial laboratory mice.

"Chance and Opportunity are proud and shy ladies who should not be told to come some other time, or, with something else on.

Max Kleiber ${ }^{16}$

This is another piece of advice that I thought it worthwhile to pass it on to the young among you. We must remember that 'chance' and 'opportunity' do not refer only to the possibility of a visit abroad, or, working under a "great person". For us clinicians, each patient and each clinical situation is an opportunity, a chance to teach us, inform us, and educate us about something. It is up to us to grab that chance and make the best use of it.

"There are] two facets of science, its ways of thinking and the tools it creates. The danger in our days is that /we have] run away with the tools leaving the way of thinking behind..."

Albert Szent-Gyorgy ${ }^{17}$

Physiologist Nobel laureate

We are living in an age of highly sophisticated and for that reason expensive, technology. It is very easy to seduced by the technology and apply it for the pleasure of doing so, or, because one does not want to be thought of as an ancient fossil who is not aware of modern techniques, or, for a marginal superiority over professional' 'rivals', or, even to get better monetary returns for the money invested on it. It is also easy to make the patient accept the hi-tec approach because "it is the latest" or even because it is the most 
expensive! In such a milieu, it is always good to keep one's goals in mind. We should remember that we use the machine or gadget and that it is not the other way round. We should not be driven by them and they cannot decide our goals. We must set up our own goals and be guided by them. Our goal has to be in human terms if it is to be meaningful and satisfying to us as human beings. It is always good to remind ourselves periodically of our aims and goals, why we are doing what we are doing.

As medical men we share a common goal with all the others in our fraternity, which transcends our super speciality, which is to reduce pain and suffering due to disease, injury or any other disorder of body and mind among our fellow humans without discriminating among them. We, as individuals, may be mere mortals unlike the Bodhisattvas, but our commitment as members of our profession, is a lasting one, like that of the Bodhisattvas.

Ladies and Gentlemen, as I said at the outset, whatever I had to say about has all been said over the years and I have hardly anything more to add to that. In this talk I therefore thought I would share with you how I found my research efforts to understand the workings of the hand actually turned out to be a long and exciting process of self-education. The award of this oration was an opportunity for me to examine this to some extent. I am extremely grateful to Prof. G. Balakrishnan and others responsible for providing me this opportunity and for honouring me with the award of this Oration. This Oration, as you all know, stands in the name of a great surgeon, who has shown what determination and hard work can achieve. Luckily for us all, he is still with us and it is my earnest desire that he will continue to be with us for many more years to inspire and challenge hand surgeons of the up-and-coming generation to surpass him if they can. I am also extremely grateful to you all for your exemplary courtesy in giving me a hearing so patiently and to the end. Thank you all.

\section{REFERENCES}

1. Pappenheimer JR. A silver spoon. Annual Rev Physiol 1987;49 :1-15.

2. Erlanger J. A physiologist reminisces. Annual Rev Physiol 1964;26:1-14.

3. Wood-Jones F. The Principles of Anatomy as Seen in the Hand. Edn. 2. London, Baillière Tindal \& Cox 1949.

4. Axelrod J. An unexpected life in research. Annual Rev Pharmacol Toxicol 1988;28:1-23.

5. Mayer JE. The way it was. Annual Rev Phys Chem 1982;33:1-23.

6. Clark WM M. Notes on half a century of research, teaching and administration. Annual Rev Biochem 1962;31:1-24.

7. Burton AC. Variety-the spice of Science as well as of life: The disadvantages of specialization. Annual Rev Physiol 1978;37:1-12.

8. Srinivasan $\mathrm{H}$. The extensor diversion graft operation for correction of intrinsic minus fingers in leprosy. J Bone Joint Surg 1973;55-B:58-65.

9. Srinivasan $\mathrm{H}$, Landsmeer JMF. Internal stabilization in the thumb. J Hand Surg [Am] 1982;7:371-75.

10. Srinivasan $\mathrm{H}$. Postural changes in thenar paralysis and their significance. J Hand Surg [Am] 1983;8:194-6.

11. Srinivasan $H$. Universe of finger postures and finger dynamography. A conceptual and methodological tool for assessing and recording the motor capacity of the finger. Hand Chir Mikrochir Plast Chir 1983;15:3-6.

12. Francis Bacon. Selected writings on the interpretation of nature. New York, Random House, 1955:151.

13. Leake CD. How I am. Annual Rev Pharmacol Toxicol 1976;16:1-14.

14. Popper K. Unended Quest-An intellectual autobiography, Glasgow, Fontana/Collins. 1978;83.

15. Vickers, Sir G. Preface to The Art of Judgement. London, Chapman \& Hall. Quoted by AC Burton (reference no. 7) 1965.

16. Kleiber M. Prefatory chapter: An old professor of animal husbandry ruminates. Annual Rev Physiol 1967;29:1-20.

17. Szent-Gyorgy A. Lost in the twentieth century. Annual Rev Biochem 1959;32:1-14. 